\title{
A RESPONSABILIDADE ÉTICO-SOCIAL DO PESQUISADOR NO BRASIL: IMPACTOS DOS DESVIOS ÉTICOS NA CONDUÇÃO DE PESQUISAS FINANCIADAS COM RECURSOS PÚBLICOS
}

\author{
Francisco Jozivan Guedes de Lima* \\ Universidade Federal do Piauí (UFPI) \\ (D) https://orcid.org/0000-0003-4483-8393 \\ Agemir Bavaresco* \\ Pontifícia Universidade Católica do Rio Grande do Sul (PUCRS) \\ (iD) https://orcid.org/0000-0002-7967-4109
}

\section{RESUMO:}

$\mathrm{O}$ artigo defende a tese da necessidade de uma base normativa nacional no Brasil acerca das normas de conduta ético-social do pesquisador objetivando regulamentar, prevenir e punir os desvios na execução de produções acadêmicas e comportamentos antiéticos de docentes e discentes. $\mathrm{O}$ ideal é que a base normativa não permaneça dependente dos Fundos de Amparo à Pesquisa apenas dos entes federativos ou de instituições isoladas.

PALAVRAS-CHAVE: Conduta ético-social; Normatividade; Pesquisa; Responsabilidade.

\section{THE ETHICAL AND SOCIAL RESPONSIBILITY OF THE RESEARCHER IN BRAZIL: IMPACTS OF ETHICAL MISCONDUCT IN DRIVING OF RESEARCHES FINANCED WITH PUBLIC FUNDS}

\begin{abstract}
:
The paper defends the thesis of the need for national normative base in Brazil about the ethical and social conduct rules to researchers. It's necessary to regulate, prevent and punish the deviations in the implementations of academic productions and the unethical conducts of the researchers. The fundamental idea is which this normative

\footnotetext{
* Doutor em filosofia e professor da Universidade Federal do Piauí (UFPI), Piauí - Brasil. Email: jozivan2008guedes@gmail.com Lattes atualizado

* Doutor em filosofia e professor da Pontifícia Universidade Católica do Rio Grande do Sul (PUCRS), Rio Grande do Sul - Brasil. E-mail: abavaresco@ pucrs.br
} 
base doesn't remain dependent only of the Research Support Funds of the federative entities or of isolated institutions.

KEYWORDS: Ethical and Social Conduct; Normativity; Research; Responsibility.

O Brasil precisará de mais uma universidade conivente? Pode-se dizer, da cultura erudita brasileira, que ela serviu e serve mais às classes dominantes, para a opressão do povo, que a outra coisa. [...] A dura verdade é que nós, universitários, temos sido e somos, também nós, coniventes com o atraso do povo brasileiro (RIBEIRO, 1995, p. 279).

\section{Introdução - um diagnóstico abrangente e os marcos iniciais}

A responsabilidade social e ética do pesquisador compreende-se, normalmente, em duas dimensões: a competência técnica e o compromisso político, ou seja, uma boa formação técnico/científica nos fundamentos e na metodologia de pesquisa e um vago "compromisso político" que ora identificase com um engajamento fraco ou com uma difusa ideia humanista abstrata. Estas duas dimensões não tratam do componente ético-social da ciência, pois além do aspecto explicativo, temos o seu caráter normativo. Então, o binômio competência técnica e compromisso político não é suficiente para explicitar o problema da responsabilidade ético-social do pesquisador. Enumeramos a título de introdução aqui algumas reflexões ou marcos iniciais deste tema como um levantamento problematizador:

(i) Compromisso ético na pesquisa: toda a pesquisa, e de modo especial as pesquisas com seres humanos, envolve problemas de ordem moral relacionados à responsabilidade ético-social do pesquisador. Um dos principais desafios é o processo de devolução dos sujeitos do conhecimento que foi produzido a partir deles, e a solução dos problemas pesquisados indo além da autorreferencialidade da pesquisa acadêmica a fim de tornar-se um conhecimento responsável para a resolução de questões sociais urgentes;

(ii) Interdisciplinaridade institucional: a responsabilidade ético-social do pesquisador consiste em exigir condições institucionais para o desenvolvimento de pesquisas interdisciplinares. A pós-graduação tem-se caracterizado pela atomização e a fragmentação no tratamento e na resolução dos problemas colocados pela sociedade. É verdade que as agências de fomento à pesquisa tais como CAPES, CNPq e as Fundações estaduais têm criado estruturas e organizações que incentivam a interdisciplinaridade, porém, é necessário que o modelo seja implementado nas Universidades e noutras estruturas de pesquisa ampliando a responsabilidade social dos pesquisadores em relação à sociedade;

(iii) Conhecimento a serviço da população (classes $C, D$ e E): há a necessidade de compreender melhor a população e a diversidade que a compõe em suas classes C, D e E. Isso implica entender sua visão de mundo, seus valores e a 
inserção em seus desafios, acumulando o conhecimento necessário para a produção de metodologias que visem dirimir seus problemas. Isso não significa que a pesquisa com as classes A e B não tenha relevância social, porém, a perspectiva dos setores populares é que mais contribui para debater e optar em favor de propostas que atendam aos interesses da maioria da sociedade. Trata-se de uma prioridade inclusiva e colaborativa que impele o pesquisador a criar conhecimento na perspectiva dos mais excluídos, sobretudo numa sociedade como a brasileira, marcada pela exclusão social (Cf. Instituto Data Popular, 2016);

(iv) Pesquisa em rede de ensino e divulgação: compete aos pesquisadores estar conectados com as Escolas de Educação Básica, aproximando pesquisadores, instituições, universidades e institutos de pesquisa. A difusão do conhecimento produzido implica a interação produtiva e a conexão em redes de conhecimento social.

(v) Perfil dos Pesquisadores: o perfil do pesquisador é o do participante em todos os níveis, organismos e instituições de gestão, mantendo sua independência face às pressões que venham a lhe corromper e a desviar-lhe de sua reponsabilidade ético-social. Então, o perfil do pesquisador deve ser o da competência técnica enquanto preparação acadêmica adequada $e \quad o d o$ compromisso político como ampliação e radicalização da democracia em todos os níveis, constituindo-se este o critério para se julgar a responsabilidade éticosocial do pesquisador (Cf. Di Giorgi, 2001);

(vi) Boas práticas na pesquisa: a responsabilidade do pesquisador insere-se numa comunidade científica regida por uma cultura de integridade ética da pesquisa fundamentada na educação, prevenção e sanções justas e rigorosas das más condutas científicas tais como fabricação, falsificação, plágio etc. (Cf. FAPESP, 2014, p. 31);

(vii) Quantidade e qualidade: o pesquisador confronta-se com um dilema crescente, de um lado, o produtivismo exigido pelas agências de pesquisa nacional e internacional, ou seja, a produção quantitativa de artigos para atender às avaliações e aos rankings competitivos de instituições estatais ou privadas, governamentais ou de mercado; de outro, a qualidade e a ética na pesquisa tal como propõe o Manifesto de Leiden sobre métricas de pesquisa ${ }^{l}$, combinando critérios quantitativos e qualitativos nas avaliações da pesquisa.

\section{Agências de fomento e amparo à pesquisa no Brasil}

Sobretudo com o suporte em nível de fomento e financiamento públicos de Fundos de Amparo à Pesquisa dos entes federativos e de instâncias nacionais

\footnotetext{
${ }^{1}$ Cf. http://www.leidenmanifesto.org/
} 
tais como a Coordenação de Aperfeiçoamento de Pessoal de Nível Superior (CAPES) e o Conselho Nacional de Desenvolvimento Científico e Tecnológico $(\mathrm{CNPq})$, as pesquisas acadêmicas no Brasil vêm gradativamente, mesmo perante crises político-institucionais e econômicas, ganhando corpo e estabilidade em nível nacional e impacto em nível internacional. Adicione-se a isso as agências internacionais de intercâmbios que oferecem bolsas de pesquisa e suporte para pesquisadores brasileiros em parcerias com agências nacionais como é o caso, por exemplo, da Fulbright ${ }^{2}$ e da Alexander von Humboldt-Foundation $(\mathrm{AvH})^{3}$.

O CNPq, atualmente uma agência do Ministério da Ciência, Tecnologia e Inovação (MCTI), foi criado incialmente como Conselho Nacional de Pesquisa a partir da Lei 1.310 de 1951 com o intuito de, conforme normatiza seu Art. $1^{\circ}$, "promover e estimular o desenvolvimento da investigação científica e tecnológica em qualquer domínio de conhecimento" ". A intenção subjacente à sua criação era a de preparar o Brasil no cenário internacional Pós-Segunda Guerra Mundial para o domínio da energia atômica. Havia, assim, na sua propositura um interesse de segurança nacional, mas que com um tempo foi se ampliando.

A CAPES, tal como o CNPq, também foi criada em 1951 a partir do Decreto $\mathrm{n}^{\circ}$ 29.741, com o objetivo de "assegurar a existência de pessoal especializado em quantidade e qualidade suficientes para atender às necessidades dos empreendimentos públicos e privados que visam ao desenvolvimento do país"5. Vinculada ao Ministério da Educação (MEC), ela trabalha de modo mais direto com a formação do quadro de pessoal com vistas à excelência, o que inclui um projeto de fortalecimento dos Programas de PósGraduação (PPG) no país. Isso implica a criação de mecanismos de transparência e controle da produtividade e da qualidade de pesquisadores (docentes e discentes) e instituições, sistematicamente submetidas a Ranking e índices de excelência. Os PPGs, por exemplo, são classificados desde o seu nível mais básico - nível três (03) - até os seus níveis máximos denominados PROEX (Programa de Excelência) que são aqueles que alcançam níveis seis (06) e sete (07). Quanto melhor a classificação, maior a possibilidade de investimento e, em termos globais, o impacto na internacionalização do Programa. Os próprios periódicos recebem uma indexação e um qualis que compreende do nível mais básico $(\mathrm{C})$, passando pelos intermediários (B5, B4,

${ }^{2}$ Cf. http://fulbright.org.br/

${ }^{3}$ Cf. https://www.humboldt-foundation.de/web/home.html

${ }^{4}$ Cf. http://cnpq.br/lei-1310/

${ }^{5}$ Cf. https://www.capes.gov.br/historia-e-missao 
B3, B2, B1), culminando no nível máximo (A2 e A1) ${ }^{6}$. PPGs que não alcançam suas metas e que repetitivamente obtêm os mesmos conceitos por avaliações quadrienais sucessivas correm o risco de descredenciamento. Em síntese, há um clima tenso para muitos, uma corrida para cumprir metas mediante a realização de eventos, publicações de artigos, capítulos de livro, etc., uma dinâmica desafiadora em que alguns podem incorrer inclusive em atos não só imorais como ilegais, como é o caso do plágio, um mau uso explícito da verba pública investida na pesquisa.

A questão é se os órgãos de fomento sejam eles da União ou dos Estados fazem um acompanhamento e uma fiscalização dessas deformidades que ameaçam a seriedade das pesquisas, deixando claro em seus estatutos as normas éticas de produtividade e as implicações penais para quem burlar tais normatividades acadêmicas. Do contrário, corre-se o risco de se ter a liberação de investimentos e fomento às pesquisas sem, por outro lado, ter-se uma devida fiscalização não só de plágio, mas do retorno limpo e justo de pesquisas financiadas.

De todo modo, não se pode perder de vista que há uma plataforma estadual (Fundos de Amparos à Pesquisa) e nacional (CNPq e CAPES) de incentivo financeiro ao desenvolvimento de pesquisas no país, algo que sem sombra de dúvidas viabiliza o progresso científico, artístico e cultural de um povo em suas variadas matrizes. Anualmente mediante via eletrônica em seus sítios e plataformas os Estados e a União lançam editais para financiar e apoiar eventos de porte local, nacional e internacional, além de outras chamadas que vão desde o incentivo à produtividade dos pesquisadores com curriculum e tempo de pesquisa e docência mais avançados até às bolsas de Iniciação Científica para alunos de graduação, além da manutenção de bolsas para discentes de pós-graduação stricto sensu, isto é, mestrado e doutorado. Institucionalmente, apesar de recursos às vezes escassos, tem-se fundos de amparo às pesquisas que devem ser continuamente pressionados a ampliar e a melhorar seus investimentos. Há inclusive entidades que exercem uma forte e legítima pressão a fim de que os investimentos não cheguem à bancarrota, como é caso, por exemplo, da Associação Nacional de Pós-Graduandos $(\mathrm{ANPG})^{7}$.

Isso não isenta de se questionar dentre vários aspectos o porquê, por exemplo, das bolsas de fomento ou do Ciências Sem Fronteiras (CsF) ter uma maior incidência, aglutinação e repasse - seguindo à lógica da tecnocracia - em áreas tidas como mais produtivas (ciências da natureza, ciências da saúde,

${ }^{6} \mathrm{Cf}$.https://sucupira.capes.gov.br/sucupira/public/consultas/coleta/veiculoPublicacaoQualis/lista ConsultaGeralPeriodicos.jsf

${ }^{7}$ Cf. http://www.anpg.org.br/ 
administração, etc.) em detrimento daquelas tidas do ponto de vista mercadológico como críticas e não-produtivas tais como as áreas de humanas e ciências sociais em seu cunho mais especulativo do que aplicado. Isso implica que as instituições de fomento à pesquisa devem estar abertas a uma reivindicação revisional por parte da comunidade acadêmica e da sociedade civil como um todo com vistas a romper com o caráter meramente tecnocrático do aparelhamento do Estado neoliberal de matriz economicista, reivindicações estas que devem apontar para um tratamento paritário do status das ciências e, consequentemente, dos repasses e investimentos. Isso impõe uma tarefa a este artigo: reconstruir as possíveis causas desse gap entre ciências da natureza e ciências humanas que constitui uma métrica no Brasil e no mundo capitalista não só para questões concernentes ao status das profissões como também para a própria política de tratamento do Governo e do Estado no tocante ao investimento e relevância para o progresso do país.

\section{A necessidade de superação do gap tecnocrático entre ciências produtivas e improdutivas nas políticas de investimentos em pesquisas e no ethos social brasileiro}

Em nível de ethos social da vida cotidiana, de modo quase que impregnado no inconsciente coletivo, muitos concordam que a medicina, o direito, a economia, a contabilidade, a administração e as engenharias são superiores à filosofia, sociologia, história, pedagogia, etc. Fazem como que um corte não epistemológico, mas de status e poder entre aquelas que são produtivas e aquelas que são improdutivas. Formar-se em medicina ou direito numa cidade do Brasil de preferência pequena e interiorana ou numa capital não cosmopolita, implica quase que automaticamente ser convidado a candidatar-se a prefeito - mesmo que o médico não tenha um tratamento minimamente humanitário para com o paciente e que o advogado não faça o mínimo de trabalho social pelos mais carentes, já que isso para ele é uma tarefa tida exclusivamente para o defensor público concursado.

Nas universidades desde os primeiros anos de graduação, estudantes são como que adestrados a fazer com que o seu curso seja visto como superior perante os demais, de modo que é necessário usar toda uma indumentária que simbolize e deixe claro aos outros qual ciência é a maior no campus. Se possível convém até mesmo colocar um distintivo da OAB ou de um Conselho Regional para ostentar poder e intimidar. São sujeitos que gostam de ser chamados de "doutores" sem ter passado por uma pesquisa e uma banca criteriosa de doutorado - uma herança perversa impregnada e patrocinada desde o século XIX na elite acadêmica brasileira que quer ser o doutor, o senhor, o 
coronel sem legitimidade para tal. E mesmo para aqueles que são doutores legitimamente o título transforma-se numa redoma de intocabilidade e infalibilidade, para não dizer de prepotência, o que demonstra claramente o déficit ético-social na formação universitária desde a sua base incipiente.

Trata-se de um vício reforçado dentro das próprias universidades, de cursos que obliteram todo o potencial social e da diaconia (serviço) do estudante e impõe-lhe um distanciamento de preferência dos mais pobres, e aí perde-se gradativamente o vínculo com a realidade e a função social da pesquisa. Há um atrofiamento dos trabalhos de extensão e uma ruptura com a comunidade, uma imunização (immunitas). A universidade transforma-se, assim, numa simples zona de conforto, numa incubadora, e criadouro de elitizados. E a pergunta sobrevém quase que naturalmente: para quê estudar, pesquisar, graduar-se, pós-graduar-se? Como superar a autorreferencialidade para não dizer egoísmo - dentro das universidades? Em que sentido as agências de fomento e o próprio Ministério da Educação podem injetar o compromisso social e solidariedade na base da formação dos discentes e como isso pode alcançar àqueles que têm o papel de fazer a mediação do processo educacional e de pesquisas, isto é, os professores? Como transformar a universidade para além dos cômputos e expectativas quantitativas? Como formar para além da tecnocracia e manutenção de lógicas excludentes? A responsabilidade social da comunidade acadêmica é um dado ineliminável, pois em especial as instituições públicas são mantidas com verbas públicas oriundas, mormente, da classe média e dos mais pobres - se se quiser imputar a responsabilidade social pelo ângulo economicista. Mesmo as não-públicas como aquelas de caráter privadocomunitário recebem investimentos públicos através de editais com vistas à manutenção de bolsas de pesquisa, etc.

Esse gap entre ciências produtivas e improdutivas no Brasil e em muitos países em termos globais, é fruto do empreendimento capitalista sedimentado na lógica tecnocrática. Produtivo é aquilo que empiricamente gera algo fabricado, visível, manipulável. É uma matriz empiricista e neoliberal de conceber a produtividade. Não se toca em ideias, elas são especulações abstratas e não ajudam o país a crescer, mas pelo contrário, travam o crescimento pois são críticas, descontroem, e não constroem. Por que filosofia, história, sociologia? Esta lógica tem soterrado todo o potencial transformador no Brasil em termos de uma agenda democrático-deliberativa.

Falando em termos habermasianos de "modelos normativos de democracia" na obra A inclusão do outro, o paradigma político brasileiro está longe de ser uma democracia deliberativa porque não credita aos cidadãos o destino da vida pública, ele está aquém de um modelo republicano porque faz uma ruptura entre o ético e político - (aqui há uma Realpolitik), mas é apenas 
um espectro neoliberal porque aqui impera a matriz economicista e o Estado é cada vez mais levado a ser um mero aparato administrativo subserviente ao sucesso econômico. Nos termos do próprio Habermas, na concepção liberal "imagina-se o Estado como aparato da administração pública, e a sociedade como sistema de circulação de pessoas em particular e do trabalho social dessas pessoas, estruturada segundo leis de mercado" (HABERMAS, 2002, p. 270).

Óbvio que se pode chegar a extremos quando se vai na contramão do individualismo caindo, assim, num fortalecimento do Estado, como é caso de Hegel na sua Rechtsphilosophie quando defende que, pela obrigação de conservar a independência e soberania do Estado, é legítimo sacrificar propriedade, vida, opiniões e tudo aquilo que faz parte do âmbito da vida, pois no seu entendimento, "há um cálculo muito equivocado, quando, na exigência desse sacrifício, o Estado é considerado apenas como sociedade civil-burguesa e como seu fim último apenas a garantia da vida e da propriedade dos indivíduos" (HEGEL, 2010, §. 324). O ideal nesse modelo de filosofia jurídica é que o indivíduo encontre sua universalidade ética (Sittlichkeit) no Estado enquanto membro (Mitglied) de uma comunidade, portanto enquanto cidadão do Estado (citoyen) e não como cidadão membro da sociedade civil-burguesa (bourgeois) enquanto comunidade de carecimentos (Bedürfnisse).

$\mathrm{O}$ aspecto positivo do liberalismo seria a sua ancoragem e defesa dos direitos fundamentais, entretanto isso torna-se desvantajoso quando a liberdade é pensada apenas em termos hobbesianos como ausência de impedimentos externos para a ação, isto é, enquanto liberdade negativa. O que conta nesse modelo é a "conservatio vitae" e a finalidade da obediência a um determinado poder estatal não é outra senão a proteção, conforme expressa o próprio Hobbes em $O$ Leviatã (2003, p, 189). É um modelo que conduz ao isolamento e o Estado transforma-se num assistente e capa protetora de direitos individuais obliterando-se, desta forma, todo o arcabouço social dos direitos, fazendo emergir um mecanismo imunitário em detrimento da communitas, falando-se em termos da biopolítica e Roberto Esposito (2010, p. 80) ${ }^{8}$.

No que concerne ao republicanismo, a sua vantagem seria a necessidade de articulação e imbricação entre o ético e o político, de modo que o bom funcionamento da polis implica a virtuosidade dos cidadãos (republicanismo cívico), entretanto, na avaliação de Habermas (2002, p. 276), a sua desvantagem consiste na condução estritamente ética dos discursos políticos,

\footnotetext{
${ }^{8}$ Conforme o próprio Esposito (2010, p. 80), "reconduzida à sua raiz etimológica, a immunitas revela-se como a forma negativa, ou privativa, da communitas: se a communitas é aquela relação que, vinculando os seus membros a um objetivo de doação recíproca, põe em perigo a identidade individual, a immunitas é a condição de dispensa dessas obrigações e, por conseguinte, de defesa ante os seus esforços expropriatórios”.
}

A responsabilidade ético-social do pesquisador no Brasil: impactos dos desvios éticos na condução de pesquisas financiadas com recursos públicos - Francisco Jozivan Guedes de Lima; Agemir Bavaresco 
recaindo assim numa certa ingenuidade e idealização de pressuposição ética. As más consequências dessa polarização entre a dimensão individual (prevalecendo a liberdade negativa) e a dimensão comunitária (prevalecendo a autonomia política e a ideia de colegisladores da coisa pública) foi bem colocada por Benjamin Constant num discurso pronunciado em 1819 no Ateneu Real de Paris:

\begin{abstract}
O perigo da liberdade antiga era que, atentos unicamente a garantir a participação no poder social, os homens não faziam muito bom uso dos direitos e gozos individuais. O perigo da liberdade moderna é o de que, absorvida pelo gozo de nossa independência privada e pela busca de nossos interesses particulares, renunciemos facilmente ao direito de participação no poder político (CONSTANT, 2015, p. 100).
\end{abstract}

Dentro do modelo de cunho economicista vivenciado na conjuntura política brasileira, é fácil de se impor verticalmente uma Proposta de Emenda à Constituição, como é o caso da PEC 241, que vise tão-somente o desenvolvimento econômico sem se perguntar sobre as perdas sociais em jogo, de modo específico, para os direitos mais básicos possíveis como saúde, educação e assistência social. Tudo feito sem a mínima discussão popular; uma PEC votada por uma elite parlamentar que sairá ilesa e beneficiária perante o pacote de ajuste fiscal. Isso é um termômetro da impotência democrática do país e da necessidade de uma reforma política urgente que injete mecanismos deliberativos populares tais como plebiscito e referendo na construção de normas para além do conclave parlamentarista e das prerrogativas dos três poderes que têm se revestido cada vez mais de um elitismo incompatível como regime democrático salvaguardado na Constituição Federal. Mecanismos estes que já existem sob previsão legal, mas que estrategicamente são obliterados das decisões políticas. A questão é: como a comunidade acadêmica no Brasil (docentes e discentes de instituições de ensino superior públicas e privadas) tem se posicionado perante tal conjuntura? Que força tem?

A própria ideia de Novo Ensino Médio no Brasil sustentada pela Medida Provisória 746/2016 é perpassada pela facultatividade do ensino de filosofia, sociologia, educação física e artes que na prática consistirá na sua gradativa expurgação curricular. A ideia de habilitar professores para lecionar numa dada área mesmo que ele não tenha formação acadêmica para tal, mas que seja enquadrado no artifício dos "saberes notáveis", viola todo o esforço dos cursos de licenciatura com a finalidade de formar quadro de excelência de docentes devidamente habilitados e credenciados pelo MEC para lecionar numa determinada disciplina. "Saberes notáveis" é um subjetivismo que abre margem para o sucateamento, tendenciosidades e para a isenção do Estado perante a 
formação de professores habilitados para o ensino; tendenciosidades no sentido que abrirá margem para a corrupção na contratação de quadro docente, pois é possível que o contratante deixe de fora um professor licenciado e favoreça um outro que não seja habilitado para uma disciplina, mas que tenha um vínculo de proximidade. Corre-se assim o risco de fragilizar o processo de imparcialidade acadêmica como, por exemplo, via concurso público suplantando-se por critérios meramente afetivos e de troca de interesses.

Todo esse processo de obliteração das ciências humanas em termos valorativos de status perante a sacralidade de outras áreas tidas como produtivas para o país, pode ser, portanto, causado por dois aspectos precípuos:

(i) uma má assimilação da divisão metódica ocorrida desde o século XIX quando Wilhelm Dilthey propôs uma especificação esquemática e metodológica entre Naturwissenschaften (ciências da natureza) e Geisteswissenschaften (ciências do espírito ou ciências humanas). O que se está em jogo nessa divisão não é propriamente uma oposição, mas uma especificidade metodológica e a necessidade para este autor de as ciências humanas terem o seu próprio método de abordagem, isto é, aquele ligado ao sentido, à compreensão, à hermenêutica, ao invés de importar o método das ciências da natureza para o estudo dos objetos das ciências humanas e de modo mais ampliado para as ciências sociais. É algo que vai justamente na contramão da intenção durkheimiana de, por exemplo, estudar os fenômenos sociais a partir dos métodos da física, isto é, das ciências naturais. De acordo com o próprio Dilthey (1992, p. 14), "a ciência analisa e desenvolve, em seguida, as relações gerais no interior de fatos homogêneos assim isolados; a religião, a poesia e a metafísica primigênia expressam o significado e o sentido do todo. Aquela conhece, estas compreendem". Essa oposição de status entre ciências da natureza e ciências humanas fruto da referida má assimilação deve ser devidamente desde os primeiros semestres de estudos na universidade onde os alunos em suas diversas áreas são induzidos equivocadamente a pensar que as humanas são inferiores porque não produzem objetos concretos e apenas teorizam, enquanto que as demais ciências produzem e abordam objetos de estudos visíveis, palpáveis, empíricos. Nesse sentido, a disciplina Metodologia da Pesquisa Científica é imprescindível para reparar tal equivocidade.

(ii) O segundo fator da disjunção entre ciências da natureza e ciências humanas em termos de status está acoplada à primeira causa: trata-se da influência do modo de produção capitalista que impõe ao Estado e às ciências uma lógica tecnocrática e toma como soberana apenas um tipo de racionalidade, a racionalidade instrumental em detrimento da racionalidade comunicativa. Claramente aqui este artigo reporta-se a Habermas em Técnica e ciência como Ideologia (1968). No diagnóstico habermasiano, a racionalidade tecnocrática 
sedimentou uma ruptura entre as esferas do trabalho (Arbeit) e da interação (Interaktion), criando uma cesura entre o mundo da técnica e o mundo ético e da política. Em prol do discurso de manutenção do capital foi marginalizada a dimensão do entendimento mútuo e da solidariedade. A racionalidade foi tomada como cálculo onde há uma relação entre meios e fins (racionalidade teleológica / Zweckrationalität), e tendo em vistas tais telos são legítimos os meios mais escusos possíveis. É uma racionalidade irrefletida que não se questiona pelas consequências da ação, se o ato é de fato justo, se é válido (gültig) intersubjetivamente para a comunidade a qual o agente está inserido. Esse é o problema da subtração do tempo das aulas de filosofia e sociologia no ensino médio no Brasil: ele retira a possibilidade de trabalhar-se uma racionalidade para além desta que impera no cotidiano: a do mundo do mercado, a tecnocrática. Ela limita a reflexão ético-política e, assim, mantém o status quo economicista cego e prescinde da formação cidadã. Ela continua a formar indivíduos técnicos, porém não devidamente preparados para a esfera pública, o que gera um processo de esvaziamento do potencial transformador em termos de solidariedade política. Nesse sentido, para Habermas é preciso evocar um novo tipo de racionalidade, a "comunicativa", que não é apenas uma habilidade para comunicar-se, mas na sua própria definição, "por racionalidade comunicativa eu entendo, por outro lado, uma interação simbolicamente mediada. Ela se orienta por normas obrigatoriamente válidas, as quais definem expectativas recíprocas de comportamento e devem ser compreendidas e reconhecidas por pelo menos dois sujeitos agentes" (HABERMAS, 2014, p. 91). O que está em jogo não é o mero convencimento, mas o entendimento mútuo e a emancipação. Nesse sentido, o "outro" não é o meu oponente a ser dobrado ou vencido, mas o meu parceiro (partner), aquele com o qual sou capaz de estabelecer um laço solidário e cooperativo tencionando construir uma sociedade mais justa e fraterna.

\section{Considerações finais - a formação ético-política do pesquisador}

Todo esse cenário de ampliação da racionalidade para além dos limites técnico-instrumentais e a busca de paridade entre as ciências, implica em termos de educação brasileira, visando o melhoramento das relações interpessoais, formar os sujeitos não para ser melhor ou superior em poder ou epistemicamente perante o outro, mas para o estabelecimento de relações solidárias, para o consenso e o dissenso respeitosos. No Brasil forma-se apenas uma competência, a técnica, e marginaliza-se uma dimensão fundamental: a ético-político. Desde sua tenra idade, os indivíduos são ensinados a obter vantagens, perder é sinônimo de fracasso, e assim cria-se um ambiente hostil de 
concorrência que está patente na sociedade civil como um todo, nas empresas, e nas próprias instituições educacionais inclusive em nível superior, onde alunos e até mesmo os docentes entram em conflito e imaturamente criam um clima tenso de convivência e para "derrubar" os colegas de profissão usam de meios antiéticos e reprováveis.

O ponto a se saber é se isso é uma questão de ordem pessoal ou algo próprio de um ethos instituído dentro das instituições e, em nível de reparação dessas patologias, se é possível e, se sim, como pode-se dirimi-las. Do contrário, corre-se o risco de uma hipocrisia: questionar ilegalidades, impeachment, corrupção, e outros danos, e, contraditoriamente, reproduzi-las no cotidiano da vida acadêmica, seja burlando, colando numa prova, plagiando um TCC, dissertação, tese, dentre outras aberrações que podem ser constatadas na vida acadêmica. Aqui reside a necessidade do fator ético e, inclusive, das suas implicações normativas para o bom funcionamento das pesquisas e da vida acadêmica como um todo.

É necessário redimensionar a formação do pesquisador no Brasil ancorando-se no imperativo de uma formação integral (uma paideia) que não descuide das dimensões do ser, conhecer, fazer, e do conviver. Isso pode ser aportado no próprio Relatório para a UNESCO da Comissão Internacional sobre Educação para o século XXI, relatado no livro "Educação: um tesouro a descobrir", organizado por Jacques Delors. A tese central é que "a educação deve contribuir para o desenvolvimento total da pessoa - espírito e corpo, inteligência, sensibilidade, sentido estético, responsabilidade pessoal, espiritualidade" (DELORS, 1998, P. 99). A própria Lei de Diretrizes e Bases da Educação nacional (LDB Lei 9. 394/96) aponta para essa necessidade de uma formação integral que não forme apenas para o mundo do trabalho, mas para as práticas sociais e para a cidadania ${ }^{9}$.

Todavia, sobretudo em tempos atuais do banimento das humanas do currículo do Ensino Médio e a tentativa de proibir a discussão de ideologias políticas e de diversidade de gênero em salas de aula do Ensino Básico e de Universidades sob o subterfúgio da "não-doutrinação", o que se vê é um retrocesso explícito no tocante à formação da dimensão ético-cidadã e o consequente fortalecimento da dimensão técnica, algo que implica um atrofiamento da formação integral estudantil e universitária no Brasil. Isso traz consequências graves para o país como a incapacidade de diálogo e consenso, enfraquecimento do potencial cooperativo, despolitização, preconceito, intolerância e violência, situações difíceis que indicam que o país está no caminho errado. Nesse modelo economicista que invade a educação através da centralidade do tecnicismo, a deformidade ética dos pesquisadores e a sua

${ }^{9}$ https://www.planalto.gov.br/ccivil_03/Leis/L9394.htm 
desvinculação e descompromisso político-social tornam-se fáceis e inculpáveis, já que não é fruto da escolha do próprio indivíduo, mas do sistema educacional que o (de)forma.

O modelo economicista leva o país a crescer para as elites em detrimento da inclusão social. Uma prova disso é o Social Progress Index (2016) que afere em nível global as (i) necessidades humanas básicas (nutrição e assistência médica, água e saneamento, habitação e segurança pessoal), (ii) fundamentos do bem-estar (acesso ao conhecimento básico, acesso à informação e comunicação, saúde e bem-estar, qualidade ambiental), (iii) e oportunidades (direito Individuais, liberdades Individuais e de escolha, tolerância e inclusão, acesso à educação superior $)^{10}$. Nele o Brasil figura na $46^{\circ}$ posição, um índice que apesar de alto tendo em vista que foram avaliados 133 países, demonstra o quanto estamos longe da equidade social, isto é, de termos um país de primeiro mundo em questões de inclusão e oportunização de qualidade de vida a todos no que concerne ao conjunto de bens mais básicos para a existência saudável da vida humana.

Contra a inatividade e distanciamento social e político dos pesquisadores perante a sociedade além-muro dos campi, é necessário implementar, desde a Educação Básica, porém de modo especial no Ensino Superior, mecanismos de extensão que levem os alunos a atuarem junto às comunidades, fazendo com o saber tenha incidência prática nos contextos nos quais devem-se engajar-se. Esse tipo de engajamento e trabalho de extensão além de romper com o academicismo autorreferencializado, retroalimenta os próprios problemas e temas de pesquisas dos docentes e discentes, além de ter a vantagem de aproximar o agente em formação da sociedade. Ir ao encontro da comunidade para além das circunscrições da universidade é um elemento indispensável que os coordenadores de curso e os órgãos responsáveis pelo trabalho de extensão devem pensar com urgência no Brasil. Na prática, o estudante de filosofia, direito, matemática, contabilidade, medicina, engenharia, etc., independente da área, todos podem realizar uma oficina, um curso, uma assistência perante, sobretudo, aos mais carentes. A função social da pesquisa é uma questão emergencial a ser pensada no Brasil, e as próprias agências de

10 "Definimos progresso social de uma maneira abrangente e extensiva. Progresso social é a capacidade de uma sociedade de atender às necessidades humanas básicas de seus cidadãos, de estabelecer as bases que permitem que indivíduos e comunidades melhorem e mantenham sua qualidade de vida, e de criar condições para que todos atinjam seu pleno potencial. Essa definição é a base das três dimensões do progresso social: Necessidades Humanas Básicas, Fundamentos de Bem-Estar, e Oportunidade”. (Índice de Progresso Social, 2016, p. 12). http://13i8vn49fibl3go3i12f59gh.wpengine.netdna-cdn.com/wp-

content/uploads/2016/07/PT_SPI-2016-Executive-Summary-2.pdf

A responsabilidade ético-social do pesquisador no Brasil: impactos dos desvios éticos na condução de pesquisas financiadas com recursos públicos - Francisco Jozivan Guedes de Lima; Agemir Bavaresco 
fomento salvaguardadas pelo MEC e pelo MCTI podem propor medidas práticas a ser implementadas nas IES.

Outro ponto central a ser trabalhado no Ensino Superior no Brasil é a criação de uma plataforma nacional relativa ao código ético que normatize e verse sobre a conduta dos pesquisadores. Se se rastreia os documentos da CAPES e CNPq, por exemplo, não se encontra uma plataforma normativa sobre isso. Um ou outro Fundo de Amparo à Pesquisa isoladamente pontuam algo acerca de um "código de boas práticas científicas" (2014), como é o caso do Fundo de Amparo à Pesquisa do Estado de São Paulo (FAPESP).

Em termos jurídicos nos códigos positivados no Brasil, há uma normatividade e suas devidas penalidades, por exemplo, que versa sobre os direitos autorais contra plágio e reprodução não autorizada de material como está claro no Art. 184 do Decreto-Lei $n^{\circ}$ 2.848/1940 recepcionado no Código Penal, e sancionado recentemente com alterações a partir da Lei $\mathrm{n}^{\mathbf{0}}$ $10.695 / 2003$, onde no seu caput está expresso que "violar direitos do autor e os que são conexos", com o devido trânsito em julgado, poderá resultar em penalidade de detenção de 3 (três) meses a 1 (um) ano, ou multa ${ }^{11}$.

Já que se tem o suporte jurídico básico previsto legalmente e positivado, fica-se mais fácil de estabelecer as normas de conduta a ser seguidas por pesquisadores. Para isso, é necessário criar um comitê interdisciplinar sob os auspícios da MEC/CAPES e do MCTI/CNPq com representatividade nacional que estabeleça depois do devido debate com a comunidade acadêmica os marcos e aspectos normativos e deontológicos precípuos com vistas à conduta ética dos pesquisadores, com normatividades que devem ir para além da pauta dos direitos autorais, incluindo em tal plataforma reivindicações imprescindíveis como a tratada ao longo deste artigo, a saber, a responsabilidade ético-social (e também política) do pesquisador, sobretudo, com vistas à superação das desigualdades sociais. Do contrário, sem essa inflexão social e um devido trabalho de extensão, os investimentos oriundos de verbas públicas advindas das pessoas mais simples e sofridas não serão devidamente revertidos e continuar-se-á formando indivíduos descompromissados com o engajamento social e comunitário, isto é, indivíduos tecnicamente habilitados, porém atrofiados nas relações humanas e no impacto social e político de suas pesquisas, indivíduos que, portanto, serão meros mantenedores do status quo capitalista e tecnocrático produtor de exclusões. Neste novo modelo normativo o conceito mercadológico da mera "concorrência" deve dar lugar aos conceitos de "cooperação" e "solidariedade". Sem essa revisão conceitual, a formação do pesquisador no Brasil não passará

${ }^{11}$ Cf. http://www.planalto.gov.br/ccivil_03/LEIS/2003/L10.695.htm\#art1art184 
de uma preparação técnica e individualista para o êxito pessoal em detrimento de outrem.

Enfim, do ponto de vista técnico e disciplinar da físcalização dos pseudopesquisadores, a criação dessa plataforma normativa comum em nível de MEC e MCTI para ser recepcionadas e aplicadas nos entes federativos, pode inclusive contar com os suportes e recursos tecnológicos e com a criação de novos mecanismos e aplicativos com vistas a identificar as possíveis fraudes e a coibir condutas antiéticas que incorrem em malversação das verbas públicas investidas em pesquisas no Brasil. Concomitante a isso, a comissão interdisciplinar deve estabelecer critérios ${ }^{12}$ claros do que seja plágio, desvio de conduta ética nas pesquisas, etc. Esse é um caminho minimamente razoável para pesquisas mais qualitativas e para uma estabilidade institucional do Ensino Superior no país para além dos meros cômputos quantitativos e dos rankings. Formar na base a conduta ético-social do pesquisador e o seu compromisso político preferencialmente para com os excluídos constitui uma conditio sine qua non para o êxito de nossas pesquisas e para universidades de excelência e de impacto internacional.

\footnotetext{
${ }^{12}$ Em nível internacional, esse debate acerca da integridade ética e do compromisso social do profissional pesquisador tem avançado em alguns pontos. Um exemplo disso, é a recente "Declaração sobre Integridade Científica na Investigação e Inovação Responsável", lançada pelas Cátedras UNESCO de Bioética da Universidade de Barcelona (UB) e da Universidade Católica Portuguesa (UCP). A integridade em tal documento é pensada a partir dos seguintes valores: honestidade no compromisso com a verdade; independência na preservação da liberdade em relação a pressões exteriores à profissão; imparcialidade na isenção ou neutralidade da prática profissional em relação a interesses sectários (CASADO et al., 2016, p. 30).
} 


\section{Referências bibliográficas}

CASADO, María (et al.). Declaração sobre Integridade Científica na Investigação e Inovação Responsável. Barcelona: Universitat de Barcelona Edicions, 2016.

CONSTANT, Benjamin. A liberdade dos Antigos comparada à dos Modernos. Trad. Emerson Garcia. São Paulo: Atlas, 2015.

DELORS, Jacques. Educação: um tesouro a descobrir - Relatório para a UNESCO da Comissão Internacional sobre Educação para o século XXI. São Paulo: Cortez Editora, 1998.

DI GIORGI, Cristiano Amaral Garboggini. A responsabilidade social do pesquisador em educação. In: Nuances. Vol. VII, setembro de 2001, p. 106 109.

DILTHEY, Wilhelm. Teorias das concepções de mundo. Trad. Artur Morão. Lisboa: Edições 70, 1992.

ESPOSITO, Roberto. Bios: Biopolítica e filosofia. Trad. M. Freitas da Costa. Lisboa: Edições 70, 2010.

FUNDAÇÃO DE AMPARO À PESQUISA DO ESTADO DE SÃO PAULO. Código de boas práticas científicas. São Paulo: FAPESP, 2014.

HEGEL, Georg Wilhelm Friedrich. Linhas fundamentais da filosofia do direito, ou direito natural e ciência do Estado em compêndio. Trad. Paulo Meneses [et al.]. São Leopoldo, RS: Ed. UNISINOS, 2010.

HABERMAS, Jürgen. A Inclusão do Outro: estudos de teoria política. Trad. George Sperber; Paulo A. Soethe. São Paulo: Edições Loyola, 2002.

HICKS, Diana; WOUTERS, Paul; WALTMAN, Ludo; RIJCKE, Sarah de; RAFOLS, Ismael. Leiden Manifesto for Research Metrics, 2015. < http://www.leidenmanifesto.org/ >.

HOBBES, Thomas. Leviatã ou matéria, forma e poder de uma república eclesiástica e civil. Trad. João Paulo Monteiro, Maria Beatriz Nizza da Silva, Claudia Berliner. São Paulo: Martins Fontes, 2003.

RIBEIRO, Darcy. O Brasil como problema. Rio de Janeiro: Francisco Alves, 1995.

\section{Sites consultados:}

< http://www.datapopular.com.br/>. Acessado em 06.04.2016.

$<$ http://www.fapesp.br/boaspraticas/FAPESP-

Codigo_de_Boas_Praticas_Cientificas_2014.pdf>. Acessado em 07.04.2016.

$<$ http://www.leidenmanifesto.org >. Acessado em 07.04.2016.

$<$ http://www.mcti.gov.br/ >. Acessado em 28.10.2016. 
< http://cnpq.br/lei-1310/ >. Acessado em 28.10.2016.

$<$ https://www.capes.gov.br/historia-e-missao >. Acessado em 28.10.2016.

$<$ https://sucupira.capes.gov.br/sucupira/public/consultas/coleta/veiculoPublicac aoQualis/listaConsultaGeralPeriodicos.jsf > . Acessado em 28.10.2016.

$<$ https://www.humboldt-foundation.de/web/home.html >. Acessado em 29.10.2016.

$<$ http://fulbright.org.br/ >. Acessado em 29.10.2016.

$<$ https://www.planalto.gov.br/ccivil_03/Leis/L9394.htm >. Acessado em 29.10.2016.

<http://13i8vn49fibl3go3i12f59gh.wpengine.netdna-cdn.com/wpcontent/uploads/2016/07/PT_SPI-2016-Executive-Summary-2.pdf >. Acessado em 29.10.2016.

$<$ http://www.socialprogressimperative.org/global-index/ >. Acessado em 29.10.2016.

< http://www.anpg.org.br/ > . Acessado em 29.10.2016.

$<$ http://www.planalto.gov.br/ccivil_03/LEIS/2003/L10.695.htm\#art1art184 >. Acessado em 30.10.2016.

\section{Contribuição dos autores:}

Francisco Jozivan Guedes de Lima e Agemir Bavaresco participaram da discussão, problematização, revisão e redação do artigo. Ambos os autores aprovaram a versão final do texto. 